\title{
Efficient expression of sortase A from Staphylococcus aureus in Escherichia coli and its enzymatic characterizations
}

Zhimeng $\mathrm{Wu}^{1,2^{*}}$, Haofei Hong ${ }^{1}$, Xinrui Zhao ${ }^{1}$ and Xun Wang ${ }^{1}$

\begin{abstract}
Background: Sortase A (SrtA) is a transpeptidase found in Staphylococcus aureus, which is widely used in site-specific protein modification. However, SrtA was expressed in Escherichia coli (E. coli) in rather low level (ranging from several milligrams to $76.9 \mathrm{mg} / \mathrm{L}$ at most). The present study aims to optimize fermentation conditions for improving SrtA expression in E. coli.
\end{abstract}

Results: Under the optimized media ( $0.48 \mathrm{~g} / \mathrm{L}$ glycerol, $1.37 \mathrm{~g} / \mathrm{L}$ tryptone, $0.51 \mathrm{~g} / \mathrm{L}$ yeast extract, MOPS $0.5 \mathrm{~g} / \mathrm{L}, \mathrm{PBS}$ buffer $180 \mathrm{~mL} / \mathrm{L}$ ) and condition $\left(30^{\circ} \mathrm{C}\right.$ for $8 \mathrm{~h}$ ) in a 7 - L fermentor, the enzyme activity and the yield of SrtA reached $2458.4 \pm 115.9 \mathrm{U} / \mathrm{mg} \mathrm{DCW}$ and $232.4 \pm 21.1 \mathrm{mg} / \mathrm{L}$, respectively, which were higher by 5.8- and 4.5-folds compared with initial conditions, respectively. The yield of SrtA also represented threefold increase than the previously reported maximal level. In addition, the enzymatic characterizations of SrtA (optimal temperature, optimal pH, the influence of metal irons, and tolerance to water-soluble organic solvents) were determined.

Conclusions: Enhanced expression of SrtA was achieved by optimization of medium and condition. This result will have potential application for production levels of SrtA on an industry scale. Moreover, the detailed enzymatic characterizations of SrtA were examined, which will provide a useful guide for its future application.

Keywords: Sortase A, Escherichia coli, Response surface methodology, 7-L fermentor, Enzymatic characterizations

\section{Background}

Sortase A (SrtA, EC number: 3.4.22.70) is a membraneanchored transpeptidase first found in Staphylococcus aureus, which anchors surface proteins to cell wall by a cell-wall sorting reaction (Mazmanian et al. 1999). It recognizes a specific sorting signal peptide (Leu-Pro-X-ThrGly, with X standing for any amino acid except cysteine) at the $\mathrm{C}$-terminal of target proteins, and cleaves the amide bond between threonine and glycine to generate a thioester intermediate; then the intermediate reacts with the amino group of pentaglycine cross-bridges resulting in the attachment of proteins to cell surface (Perry et al. 2002a, b). SrtA is a promiscuous enzyme, which can accept a

\footnotetext{
*Correspondence: zwu@jiangnan.edu.cn

${ }^{1}$ The Key Laboratory of Carbohydrate Chemistry and Biotechnology, Ministry of Education, School of Biotechnology, Jiangnan University, 1800 Lihu Road, Wuxi, China

Full list of author information is available at the end of the article
}

variety of oligoglycine-modified nucleophiles as its substrate (Bentley et al. 2008). In addition, the truncated SrtA $(\Delta 59$ SrtA), by removing its original $\mathrm{N}$-terminal transmembrane domain, showed good water solubility and retained the same transpeptidation activity as full-length SrtA (Ilangovan et al. 2001). Therefore, in recent years, SrtA-mediated ligation (SML) was widely used in proteinto-protein fusions (Witte et al. 2012), peptide and protein cyclizations (Wu et al. 2011), immobilization of biocatalyst onto solid surface (Chan et al. 2007), preparation of complex glycoconjugates (Guo et al. 2009), antibody-drug conjugation (Beerli et al. 2015,Voloshchuk et al. 2015), and in vivo protein modification (Glasgow et al. 2016).

With the development of SML, the demand for highlevel expression of SrtA is very high. E. coli are the most studied expression system for SrtA production because of its effective genetic manipulation and cheap culturing cost (Vincentelli and Romier 2013). Since the 
recombinant $\Delta 59$ SrtA was first achieved in 1999 using pQE30 (Qiagen) as vector in E. coli (Ton-That et al. 1999), several groups have cloned and expressed SrtA using several commercial plasmids, including pET23b (Novagen) (Guo et al. 2009), pTWIN1 (New England Biolabs) (Bentley et al. 2008) and pBAD (Invitrogen) (Kim et al. 2002), etc., with slightly modified protocols. However, the reported yield of SrtA varied differently and remained at low level ranging from several milligrams to the maximum of $76.9 \mathrm{mg} / \mathrm{L}$ (Kruger et al. 2004). In our ongoing studies on SML for the synthesis of complex glycoconjugates (Wu et al. 2010, 2013), we realized that the low-level production of SrtA is difficult to meet the requirement of future industrial applications. Therefore, more endeavors should be made to improve the expression level of this important enzyme.

Heterologous expression of recombinant protein in $E$. coli is influenced by many factors, including medium composition, induction temperature, initial $\mathrm{pH}$, and so on (Lee et al. 1997). In this study, $\Delta 59$ SrtA was cloned and successfully expressed in E. coli at first. Then, the optimization of fermentation conditions for SrtA production was manipulated by the combination of traditional onefactor-at-a-time approach and response surface methodology (RSM) at shake-flask stage, which is an effective and simplified method that has gained great success in the production of recombinant proteins (Papaneophytou and Kontopidis 2014). Finally, high-level expression of $\Delta 59$ SrtA was achieved in a 7-L fermentor, and the enzymatic characterizations of SrtA were examined.

\section{Methods}

\section{Strain, plasmid, and media}

The host strain E. coli BL21 (DE3) and plasmid pET28a were purchased from Novagen (Madison, WI). Luria broth (LB) medium (Tryptone $10 \mathrm{~g} / \mathrm{L}$, Yeast extract $5 \mathrm{~g} / \mathrm{L}, \mathrm{NaCl}$ $10 \mathrm{~g} / \mathrm{L}$ ), Terrific broth (TB) medium (Tryptone $12 \mathrm{~g} / \mathrm{L}$, Yeast extract $24 \mathrm{~g} / \mathrm{L}$, Glycerol $4 \mathrm{~g} / \mathrm{L}$ ) with $100 \mathrm{~mL} / \mathrm{L}$ PBS buffer $\left(\mathrm{K}_{2} \mathrm{HPO}_{4} \cdot 3 \mathrm{H}_{2} \mathrm{O} 164.3 \mathrm{~g} / \mathrm{L}, \mathrm{KH}_{2} \mathrm{PO}_{4} 23.1 \mathrm{~g} / \mathrm{L}\right)$, Super broth $(\mathrm{SB})$ medium (Tryptone $30 \mathrm{~g} / \mathrm{L}$, Yeast extract $20 \mathrm{~g} / \mathrm{L}$, 3-(N-Morpholino) propanesulfonic acid (MOPS) $10 \mathrm{~g} / \mathrm{L}$ ), Soybean-peptone-yeast extract broth (SOB) medium (Tryptone $20 \mathrm{~g} / \mathrm{L}$, Yeast extract $5 \mathrm{~g} / \mathrm{L}, \mathrm{NaCl} 0.5 \mathrm{~g} / \mathrm{L}, \mathrm{KCl}$ $0.2 \mathrm{~g} / \mathrm{L})$ and $2 \times$ Yeast extract/tryptone $(2 \times \mathrm{YT})$ medium (Tryptone $16 \mathrm{~g} / \mathrm{L}$, Yeast extract $10 \mathrm{~g} / \mathrm{L}, \mathrm{NaCl} 5 \mathrm{~g} / \mathrm{L}$ ), were used to perform the expression of SrtA, respectively.

\section{Expression of SrtA in E. coli BL21 (DE3)}

The genome of $S$. aureus was extracted by Genomic Extraction Kit (Qiagen, Valencia, CA, USA) and applied as the template for amplifying $\triangle 59-$-srtA with the primer pairs: CAT GCC ATG GAA GCT AAA CCT CAA ATT CCG; and CGC GGA TCC TTA GTG GTG GTG
ATG ATG ATG TTT GAC TTC TGT AGC TAC AAA GAT. The gel-purified PCR-amplified $\triangle 59$-srtA fragments were digested and inserted into the $\mathrm{NcoI} / \mathrm{BamHI}$ site of pET28a. The plasmid (pET28a- $\Delta 59$-srtA) confirmed by DNA sequencing was transformed into $E$. coli BL21 (DE3) strain. The positive clones were propagated in LB medium at $37^{\circ} \mathrm{C}$ overnight with constant shaking at $200 \mathrm{rpm}$. The seed culture $(2 \%)$ was inoculated into $25 \mathrm{~mL}$ fermentation medium at $37^{\circ} \mathrm{C}$ until the $\mathrm{OD}_{600}$ reached 0.6 and then incubated with $1 \mathrm{mM}$ IPTG (isopropyl $\beta$-D-thiogalactoside) at $25{ }^{\circ} \mathrm{C}$ for $8 \mathrm{~h}$. When the fermentation was completed, cells were pelletized and ultrasonicated by a probe VCX800 system (Sonics, Newtown, USA). The lysate supernatant were collected for the activity assay and purification.

\section{SrtA activity assay}

The specific substrate of SrtA (Dabcyl-QALPETGEEEdans) was obtained from GL biochem Ltd. (Shanghai, China). The SrtA activity arrays were performed in 200$\mu \mathrm{L}$ volume of $50 \mathrm{mM}$ Tris- $\mathrm{HCl}$ buffer (including $150 \mathrm{mM}$ $\mathrm{NaCl}, 30 \mathrm{mM} \mathrm{CaCl}_{2}, 0.5 \mathrm{mg}$ Dabcyl-QALPETGEE-Edans, $\mathrm{pH} 7.8$ ), and $10 \mu \mathrm{L}$ SrtA lysate supernatant. The reactions were carried out at $37^{\circ} \mathrm{C}$ for $1 \mathrm{~h}$ by means of a Synergy $\mathrm{H} 4$ hybrid microplate reader (BioTek, Vermont, America), and the fluorescence intensity (FI) was detected with $350 \mathrm{~nm}$ for excitation and $495 \mathrm{~nm}$ for recordings. One unit of SrtA activity was defined as the amount of enzyme (mg) that was able to increase at the rate of one FI per minute in the $200-\mu \mathrm{L}$ reaction mixture.

\section{Purification of SrtA}

The lysate supernatant and Ni-NTA agarose (Qiagen, Hilden, Germany) were loaded onto a gravity-flow column and incubated for $4 \mathrm{~h}$ at $4{ }^{\circ} \mathrm{C}$. Then, the agarose was washed with a stepwise gradient of imidazole (10$40 \mathrm{mM}$ ) to eliminate intracellular contaminating proteins. The C-terminal His-tagged SrtA was eluted from the column using $500 \mathrm{mM}$ imidazole and desalted using an Amicon Ultra $3 \mathrm{~K}$ device (Millipore, Billerica, USA). The concentration of purified SrtA was determined by the Bradford method and was used to calculate the yield of SrtA for each sample.

\section{Single-factor optimization}

The optimal medium and several important fermentation conditions (induction time, induction temperature, and initial $\mathrm{pH}$ ) for SrtA production were obtained by single factor optimization in $250-\mathrm{mL}$ shaking flasks containing $25 \mathrm{~mL}$ of sterilized medium. The concentrations of alternative carbohydrates and nitrogenous compounds were equivalent to the concentrations of carbon and nitrogen resources in the initial medium $(12 \mathrm{~g} / \mathrm{L}$ tryptone; $4 \mathrm{~g} / \mathrm{L}$ 
glycerol). In each experiment, one factor was changed, while the other factors were held constant. After fermentation, cell growth was monitored by measuring $\mathrm{OD}_{600}$ and correlated it with dry cell weight (DCW); the intracellular SrtA activity was measured by the method described in SrtA activity assay. Each experiment was performed in triplicate for the biological replicates, and the average values of enzymatic activity and biomass were used to select the optimal medium and conditions.

\section{Plackett-Burman Design}

In order to enhance SrtA production, it is necessary to select those variables with major effects at first. Applying Plackett-Burman Design, fractional two-level factorial designs can be used for the efficient and economical screening. Experimental design was formulated according to the Plackett-Burman Design tool of Design Expert 7.0 software (Statease, USA) for the selection of significant factors. Nine factors were selected (the concentration of glycerol, tryptone, yeast extract, PBS buffer, and MOPS in the medium, induction occasion, the concentration of IPTG, inoculation, loading volume), each of which was coded with two levels (Table 1). The twelve experiments were performed in shaking-flask fermentation under conditions fixed by single factor optimization (all cultivations were carried out in $250 \mathrm{~mL}$ shake flasks at $200 \mathrm{rpm}$ ). All experiments were performed in triplicates, and the average values of enzymatic activity and biomass were used to select the optimal medium and conditions. The $P$ values were calculated by Duncan's multiple range tests. The optimal values of non-significant factors were determined by the prediction tool of Design Expert 7.0.

\section{Box-Behnken Design}

Box and Behnken Design can propose three level designs for fitting response surfaces to get the best values for different variables by second-order polynomial model. Therefore, the concentration of three significant factors (glycerol, tryptone, and yeast extract) in the medium was optimized by the Box-Behnken Design tool of Design
Expert 7.0 software. Each factor was coded with three levels (Additional file 1: Table S1) and seventeen experiments were performed in shaking-flask fermentation under previous fixed conditions (all cultivations were carried out in $250 \mathrm{~mL}$ shake flasks at $200 \mathrm{rpm}$ ). All experiments were performed in triplicates, and the average values of enzymatic activity and biomass were used to select the optimal medium and conditions. The $P$ values were calculated by Duncan's multiple range tests. The optimal concentrations of glycerol, tryptone, and yeast extract were determined by the prediction tool of software.

\section{The enzymatic characterizations of SrtA}

The effect of $\mathrm{pH}$ on SrtA activity was measured in the $200 \mu \mathrm{L}$ reaction system at $37^{\circ} \mathrm{C}(150 \mathrm{mM} \mathrm{NaCl}, 10 \mathrm{mM}$ $\mathrm{CaCl}_{2}, 0.5 \mathrm{mg}$ Dabcyl-QALPETGEE-Edans) in a $\mathrm{pH}$ range of 3.0-11.0, using the appropriate buffers at concentration of $50 \mathrm{mM}$ (3.0-5.0, sodium citrate; $6.0-8.0$, sodium phosphate; 8.0-9.0, Tris- $\mathrm{HCl} ; 10.0-11.0$, and $\left.\mathrm{NaHCO}_{3}-\mathrm{NaOH}\right)$. The optimal temperature for SrtA activity was determined at various temperatures ranging from 20 to $80{ }^{\circ} \mathrm{C}$. To determine the effect of metal ions on SrtA activity, the enzyme assays were measured without additional metal ion (control) or with $5 \mathrm{mM}$ different metal ions $\left(\mathrm{Ca}^{2+}, \mathrm{Mn}^{2+}, \mathrm{Mg}^{2+}, \mathrm{Co}^{2+}, \mathrm{Cu}^{2+}, \mathrm{Fe}^{2+}\right.$, $\mathrm{Ni}^{2+}$ and $\mathrm{Zn}^{2+}$ ). As for the optimal concentration of $\mathrm{Ca}^{2+}$, the SrtA activities were detected at a concentration ranging from $1 \mathrm{mM}$ to $100 \mathrm{mM}$. At last, the effect of soluble organic solvents (acetone, methanol, ethanol, acetonitrile, and dimethyl sulfoxide) on SrtA activity were determined, the enzyme assays were measured at a content of ranging from 10 to $50 \%$. All experiments were performed in triplicate, and the mean values were used for calculations.

\section{Results and discussion}

Selection of the components of fermentation medium by single factor optimization

Fermentation medium has a profound influence on the expression of recombinant proteins in $E$. coli among many

Table 1 The Plackett-Burman design and effects of nine factors for SrtA production

\begin{tabular}{|c|c|c|c|c|c|c|}
\hline Factors & Code & High level $(+1)$ & Low level $(-1)$ & Coefficient & $F$ value & $P$ value \\
\hline Glycerol (g/L) & A & 1.0 & 0.1 & -162.08 & 27.97 & 0.03 \\
\hline Tryptone (g/L) & $B$ & 4.0 & 1.0 & -243.91 & 63.35 & 0.02 \\
\hline Yeast extract (g/L) & C & 4.0 & 1.0 & -201.77 & 43.35 & 0.02 \\
\hline PBS (\%) & D & 20.0 & 5.0 & -17.02 & 0.31 & 0.63 \\
\hline MOPS (g/L) & $E$ & 1.5 & 0.5 & -85.82 & 7.84 & 0.11 \\
\hline Induction occasion $\left(\mathrm{OD}_{600}\right)$ & $F$ & 1.0 & 0.4 & 113.59 & 13.74 & 0.07 \\
\hline IPTG (mM) & G & 1.5 & 0.2 & 33.43 & 1.19 & 0.39 \\
\hline Inoculation (\%) & $\mathrm{H}$ & 5.0 & 1.0 & -4.80 & 12.83 & 0.89 \\
\hline Loading volume (\%) & 1 & 20.0 & 6.0 & -109.76 & 0.03 & 0.07 \\
\hline
\end{tabular}


factors [Tseng and Leng 2012, Li et al (2014)]. Thus, starting from the $E$. coli BL21 (DE3) strain encoding pET28a- $\Delta 59$ srtA plasmid, five media (LB, TB, SOB, SB and $2 \times Y$ T) were screened to express SrtA at shaking-flask level at $37^{\circ} \mathrm{C}$ for $4 \mathrm{~h}$ in an initial experiment. As shown in Fig. 1a, when expressed in TB and SB media, the SrtA activity values were 1245.2 and $1210.7 \mathrm{U} / \mathrm{mg}$ DCW, respectively, which were higher than those in LB, SOB, and $2 \times$ YT media (855.2, 783.2 and 1032.9 $\mathrm{U} / \mathrm{mg}$ DCW, respectively). This result indicated that using the rich media improved the expression level of SrtA. By comparing the medium compositions of TB and SB, defined components may affect the SrtA expression level. Therefore, glycerol, PBS buffer, and MOPs were added into the control media $(12 \mathrm{~g} / \mathrm{L}$ tryptone and $24 \mathrm{~g} / \mathrm{L}$ yeast extract), which were used as fermentation medium in SrtA expression, respectively. It was interesting to observe that the addition of glycerol and PBS enhanced the enzymatic activities by 18.3 and $17.3 \%$, respectively. Addition of MOPS increased the SrtA activity by $23.5 \%$ (Fig. 1b). Thus, we choose TB medium $(12 \mathrm{~g} / \mathrm{L}$ tryptone, $24 \mathrm{~g} / \mathrm{L}$ yeast extract, $4 \mathrm{~g} / \mathrm{L}$ glycerol, and $100 \mathrm{~mL} / \mathrm{L}$ PBS buffer) with the addition of $10 \mathrm{~g} / \mathrm{L}$ MOPS as the initial SrtA fermentation medium.

Because both carbon and nitrogen sources are important nutrients in the media for protein expression (Scott et al. 2002), these two nutrients were screened to find the optimal alternatives for SrtA expression. Five different types of carbohydrates (glucose, fructose, galactose, maltose, lactose, sucrose, dextrin, and starch) and nine nitrogenous compounds (beef extract, soya peptone, fishmeal, casein, urea, ammonium chloride, ammonium

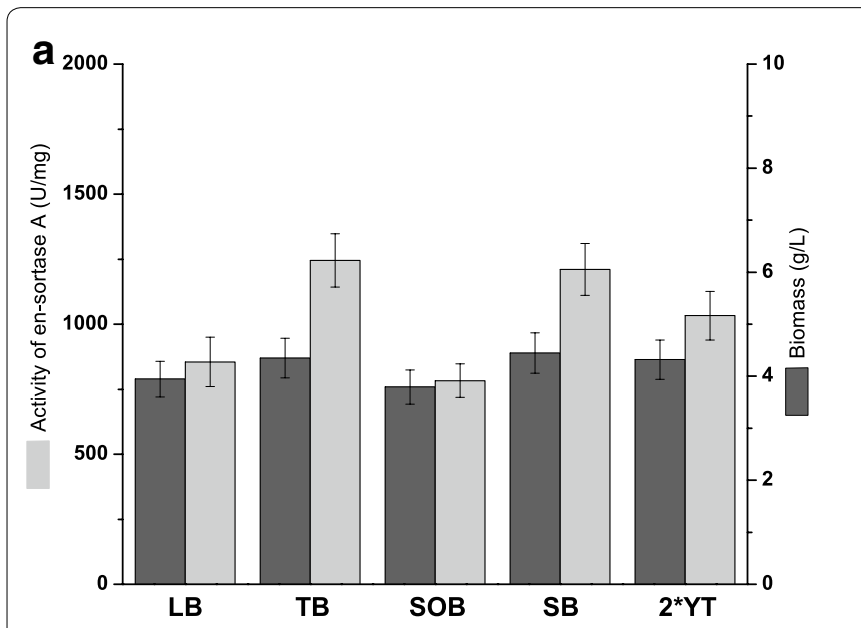

b
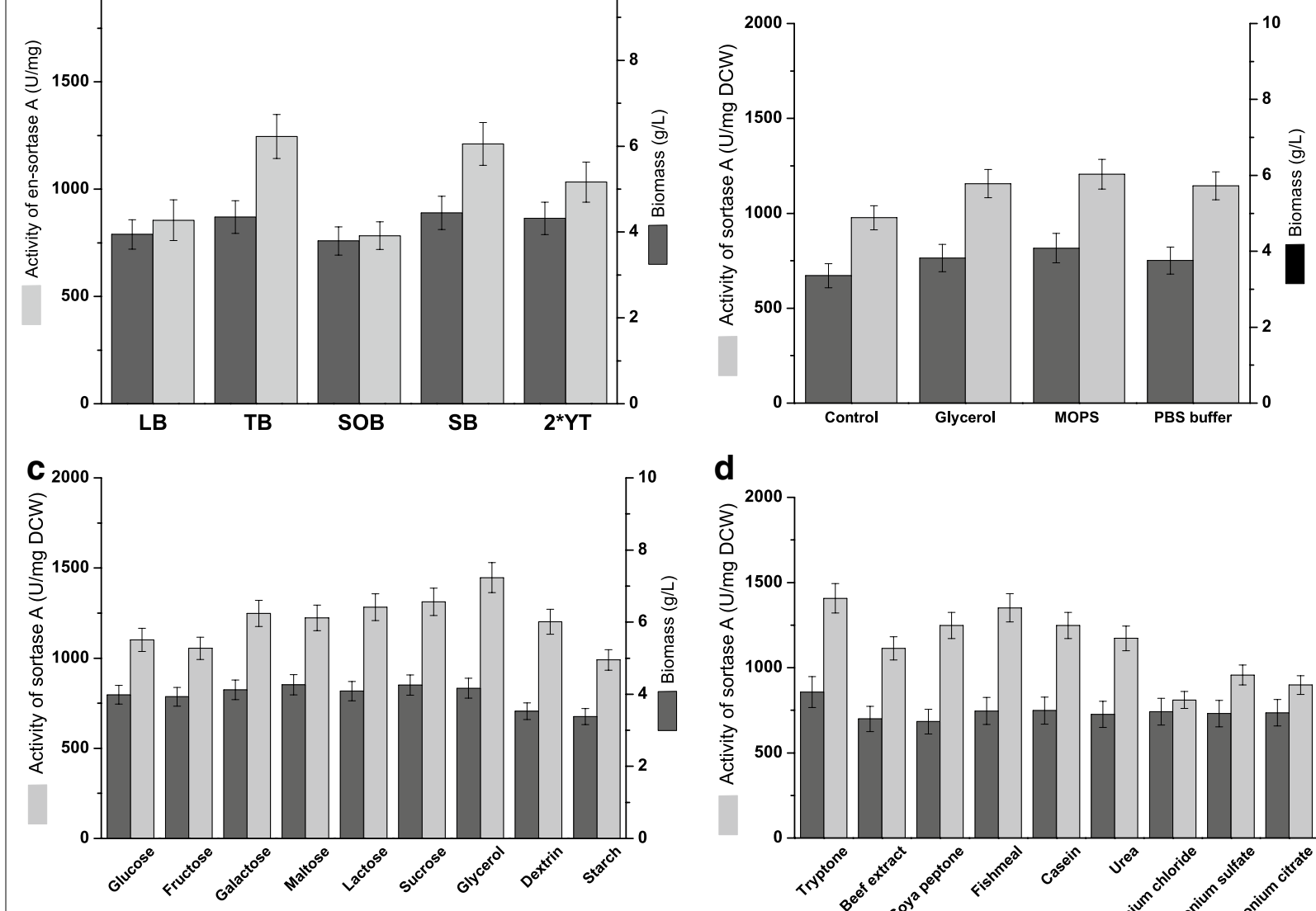

d

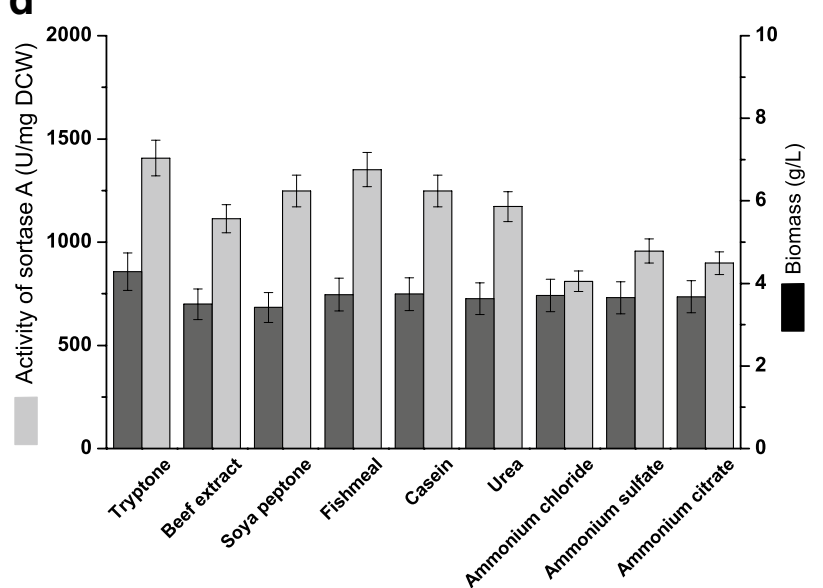

Fig. 1 a Effects of media on the cell growth and SrtA expression. Light gray and dark gray bars represent the SrtA activity and biomass in mediums of $L B, T B, S O B, S B$ and $2 \times Y T$. $\mathbf{b}$ Effects of addition of defined compositions in media on the expression of SrtA. Light gray and dark gray bars represent the SrtA activity and biomass in the TB medium with addition of glycerol, MOPS, and PBS buffer. The TB medium without glycerol and PBS buffer was used as the control. $\mathbf{c}$ Effects of various carbon sources on the expression of SrtA. Light gray and dark gray bars represent the SrtA activity and biomass in the medium with various carbon sources of glucose, fructose, galactose, maltose, lactose, sucrose, glycerol, dextrin, and starch. $\mathbf{d}$ Effects of nitrogen sources on the expression of SrtA. Light gray and dark gray bars represent the SrtA activity and biomass in the medium with various nitrogen sources of tryptone, beef extract, soya peptone, fishmeal, casein, urea, ammonium chloride, ammonium sulfate, and ammonium citrate 

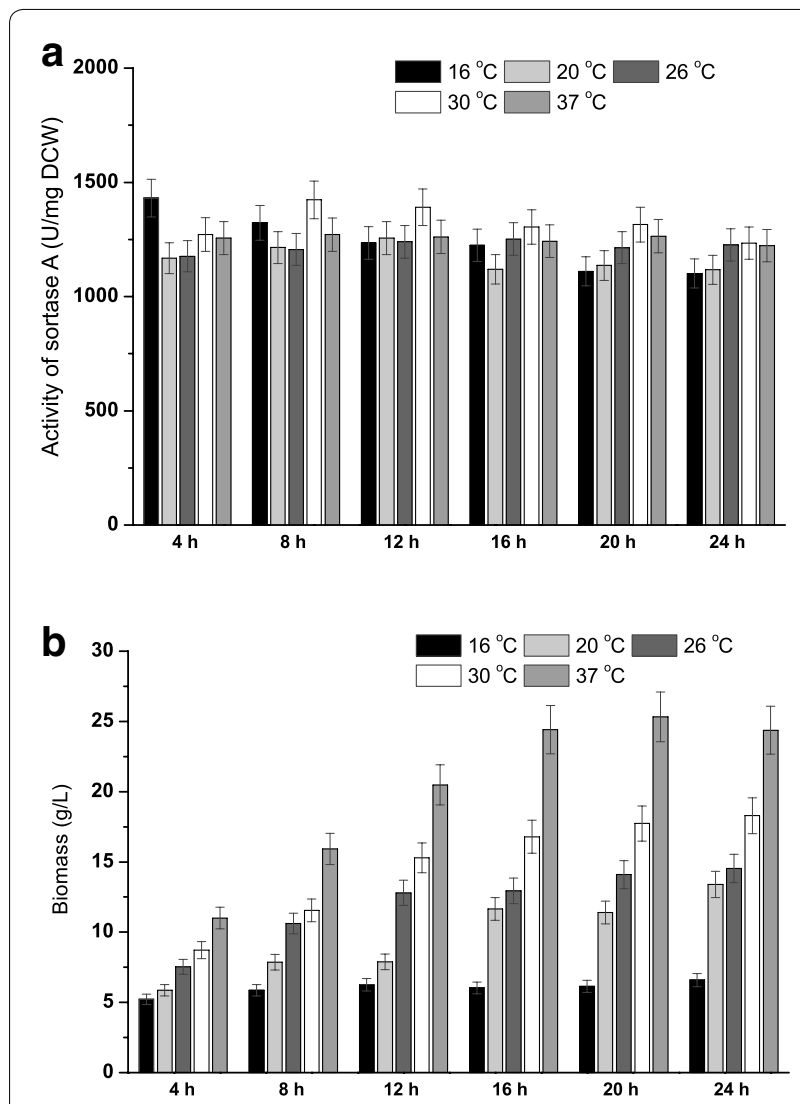

Fig. 2 Effects of induction time and induction temperature on the expression of SrtA. a The SrtA activities under various induction times and induction temperatures; $\mathbf{b}$ the biomasses under various induction times and induction temperatures

sulfate, and ammonium citrate) were used to replace the primary carbon and nitrogen sources in TB medium. As shown in Fig. 1c, glycerol was the suitable carbon source for SrtA expression which showed the best strain growth and enzymatic activity (1446.7 U/mg DCW). As for the nitrogen source, organic nitrogen source was superior to inorganic nitrogen source. As Fig. 1d shows, tryptone was the most suitable nitrogen source for SrtA expression, which gave the highest values of cell biomass and enzymatic activity (1407.1 U/mg DCW). Hence, glycerol and tryptone were selected in the subsequent experiments.

\section{Influences of induction time, induction temperature, and initial $\mathrm{pH}$ on SrtA production}

After the fermentation medium was optimized, the induction time, induction temperature, and initial $\mathrm{pH}$ were revisited as these parameters varied greatly in previous reports (Ton-That et al. 1999; Hirakawa et al. 2012; Lee et al. 2002). In previous study on SrtA expression, higher induction temperature $\left(37^{\circ} \mathrm{C}\right)$ (Ilangovan et al. 2001) and shorter induction time (within $6 \mathrm{~h}$ ) (Kim et al. 2002) were mostly applied. However, it was found that the lower induction temperature (below $30{ }^{\circ} \mathrm{C}$ ) (Tanaka et al. 2008) and longer induction time (more than $8 \mathrm{~h}$ ) (Matsushita et al. 2009) is helpful for SrtA production. In this study, induction time $(4,8,12,16,20$ and $24 \mathrm{~h})$ and induction temperature (16, 20, 26, 30 and $37^{\circ} \mathrm{C}$ ) were combined to perform shakingflask fermentation (Fig. 2). The highest SrtA activity (1431.3 $\mathrm{U} / \mathrm{mg} \mathrm{DCW}$ ) was obtained at $16^{\circ} \mathrm{C}$ for $4 \mathrm{~h}$ (Fig. 2a), but the strain growth was extremely poor under this condition (Fig. 2b). Therefore, to maintain sufficient cell density for SrtA expression, fermentation at $30^{\circ} \mathrm{C}$ for $8 \mathrm{~h}$ (the second highest SrtA activity) was chosen as the optimal condition in the following experiments. As for initial $\mathrm{pH}$, another important factor for the heterogeneous expression in E. coli (Buchanan and Klawitter 1992), strain growth was inhibited when $\mathrm{pH}$ was below 6.0 or above 9.0; while SrtA activity reached the highest enzymatic activity (1411.4 U/ mg DCW) when pH was 7.0 (Fig. 3). Therefore, the optimal initial $\mathrm{pH}$ was chosen at $\mathrm{pH}$ 7.0.

\section{Determination of significant factors for SrtA production by Plackett-Burman design}

Besides the optimal parameters mentioned above, there are still many factors that influence SrtA production. Based on the SrtA activity of each experiment designed by the principle of Plackett-Burman, the effect of these factors were evaluated (Additional file 1: Table S2). The fitted equation (in coded value) was obtained from the twelve tests based on the first-order model:

$$
\begin{aligned}
Y(\text { sortase A activity) }= & 645.67-162.08 \times \mathrm{A}-243.91 \times \mathrm{B} \\
& -201.77 \times \mathrm{C}-17.02 \times \mathrm{D}-85.82 \\
& \times \mathrm{E}+113.59 \times \mathrm{F}+33.43 \times \mathrm{G} \\
& -4.80 \times \mathrm{H}-109.76 \times \mathrm{I}
\end{aligned}
$$

The coefficient of determination $\left(R^{2}=0.9884\right)$ indicates that $98.84 \%$ of model terms satisfy the model, and the fitting degree of the regression equation is good. The results revealed that the concentration of glycerol, tryptone, yeast

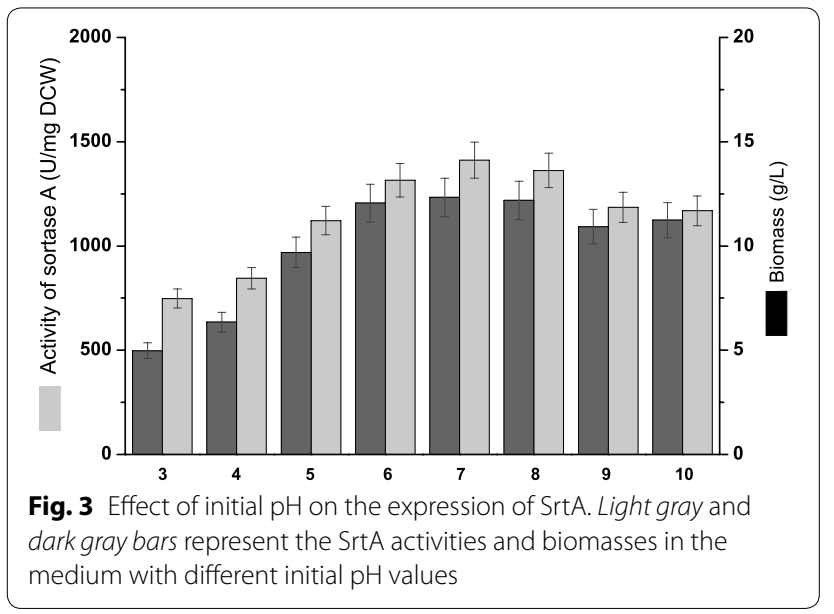


extract are the significant factors $(P$ value $<0.05)$ and the other six factors have weaker effect $(P$ value $>0.05)$. Forecasted by Design-Expert software, the value of these six nonsignificant factors are defined as IPTG $1.5 \mathrm{mM}$, MOPS $0.5 \mathrm{~g} / \mathrm{L}, \mathrm{PBS}$ buffer $180 \mathrm{~mL} / \mathrm{L}$, induction occasion $\left(\mathrm{OD}_{600}\right)$ 1.0, inoculum $2 \%$, and loading volume $10 \%$. Furthermore, the negative coefficients of glycerol $(-162.08)$, tryptone $(-243.91)$, and yeast extract $(-201.77)$ indicated that the low concentrations of glycerol, tryptone, and yeast extract were beneficial for SrtA production.

\section{Box-Behnken design results for the significant factors}

In the following, Box-Behnken design was applied to refine the optimal levels of three selected significant factors (glycerol, tryptone, and yeast extract) for SrtA production. The high levels of glycerol, tryptone, and yeast extract were maintained at $4.0 \mathrm{~g} / \mathrm{L}$, while their low levels were reduced into $0.5 \mathrm{~g} / \mathrm{L}$. Seventeen experiments were performed in shaking-flask fermentation under previously fixed conditions (Table 2). The experimental data were fitted to obtain the second-order polynomial model (in coded value) equation:

$$
\begin{aligned}
Y(\text { sortase A activity })= & 1479.80+18.11 \times \mathrm{A}-265.51 \times \mathrm{B} \\
& -67.58 \times \mathrm{C}-1.57 \times \mathrm{AB}+22.40 \\
& \times \mathrm{AC}+33.35 \times \mathrm{BC}-12.06 \times \mathrm{A}^{2} \\
& -269.56 \times \mathrm{B}^{2}+45.81 \times \mathrm{C}^{2}
\end{aligned}
$$

The results of ANOVA (analysis of variance) are summarized in Additional file 1: Table S3. The value of $R^{2}$ is 0.9833 , suggesting that $98.33 \%$ of model terms satisfy the

Table 2 The Box-Behnken design matrix and experimental results

\begin{tabular}{lrrrr}
\hline Runs & \multicolumn{1}{c}{ A } & \multicolumn{1}{c}{ B } & \multicolumn{1}{c}{ C } & SrtA production (U/mg DCW) \\
\hline 1 & 0 & 0 & 0 & 1491.1 \\
2 & 0 & -1 & +1 & 1394.1 \\
3 & +1 & -1 & 0 & 971.6 \\
4 & +1 & 0 & +1 & 912.2 \\
5 & -1 & -1 & 0 & 1418.7 \\
6 & 0 & 0 & 0 & 1468.3 \\
7 & 0 & +1 & +1 & 1505.3 \\
8 & -1 & 0 & -1 & 1666.6 \\
9 & 0 & +1 & -1 & 1588.2 \\
10 & +1 & 0 & -1 & 988.1 \\
11 & -1 & +1 & 0 & 1427.9 \\
12 & +1 & +1 & 0 & 974.5 \\
13 & 0 & 0 & 0 & 1464.8 \\
14 & 0 & -1 & -1 & 1566.6 \\
15 & -1 & 0 & +1 & 1457.3 \\
16 & 0 & 0 & 0 & 1492.4 \\
17 & 0 & 0 & 0 & 1482.4 \\
\hline
\end{tabular}

model and the equation was suitable for representing the experimental data. Compared with the Plackett-Burman design results, the Box-Behnken design results further confirmed the significant negative effects of tryptone and yeast extracts on the SrtA production (both $P$ values $<0.01$ ), while the effect of glycerol was not apparent $(P$ value $>0.05)$. The interaction of the three factors were further analyzed, and the 3D surface plots are shown in Fig. 4. Based on the

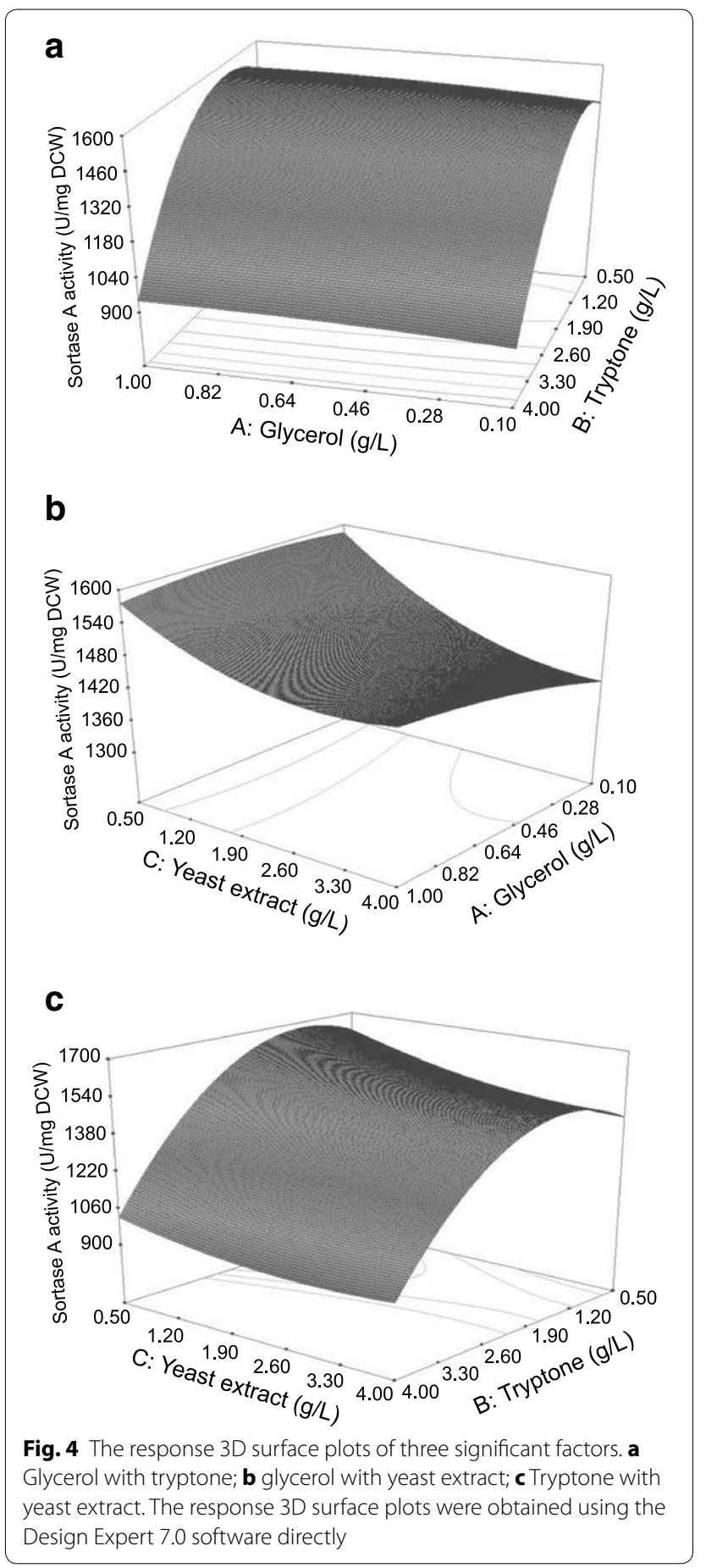


credible model equation, the maximum SrtA production (1674 U/mg DCW predicted) could be obtained at $0.48 \mathrm{~g} / \mathrm{L}$ glycerol, $1.37 \mathrm{~g} / \mathrm{L}$ tryptone, and $0.51 \mathrm{~g} / \mathrm{L}$ yeast extract.

To verify this model, SrtA expression was performed in a 7-L fermentor under the predicted optimal medium and conditions. The enzyme activity and yield of SrtA were $2458.4 \pm 115.9 \mathrm{U} / \mathrm{mg}$ DCW and $232.4 \pm 21.1 \mathrm{mg} / \mathrm{L}$, respectively. Compared with the control (LB medium) and initial conditions $\left(37^{\circ} \mathrm{C}\right.$ for $4 \mathrm{~h}$ ), the enzyme activity and yield of SrtA were increased by 5.8 - and 4.5 -folds, respectively (Fig. 5a, b; Table 3). And to the best of our knowledge, this result represented the highest yield of SrtA expression ever reported, which is threefold increase compared with the highest production of SrtA in literature (76.9 mg/L) (Naik et al. 2006).

\section{The enzymatic characterizations of Srt A}

SrtA-mediated ligation has been widely used in site-specific protein modification in recent years. However, to our knowledge, the enzymatic characterizations of SrtA were explored incompletely. These parameters are particularly important for the application of SrtA in ligation reactions. The optimal $\mathrm{pH}$ of SrtA activity was measured from $\mathrm{pH}$ 3-11 using FRET substrate Dabcyl-QALPETGEE-Edans. SrtA retained good activity over a $\mathrm{pH}$ range of 7.0-9.0 and displayed the optimal activity at $\mathrm{pH} 8.0$ (Fig. 6a). For thermostability, SrtA remained its $50 \%$ of activity over a range of $20-60{ }^{\circ} \mathrm{C}$ and the optimal temperature was $35{ }^{\circ} \mathrm{C}$ (Fig. 6b). SrtA was $\mathrm{Ca}^{2+}$-dependent enzyme. However, the influence of other metal irons $\left(\mathrm{Co}^{2+}, \mathrm{Cu}^{2+}, \mathrm{Fe}^{2+}, \mathrm{Mg}^{2+}, \mathrm{Mn}^{2+}, \mathrm{Ni}^{2+}\right.$, and $\left.\mathrm{Zn}^{2+}\right)$ and the most suitable concentration of $\mathrm{Ca}^{2+}$ to the activity of SrtA were unknown. With regard to the influence of metal irons, although $\mathrm{Ca}^{2+}$ has been proven to be necessary for SrtA activity and $5-10 \mathrm{mM} \mathrm{Ca}^{2+}$ was added in previous SrtA-catalyzed reactions (Wu et al. 2013), the effects of other metal irons (such as $\mathrm{Mn}^{2+}, \mathrm{Cu}^{2+}, \mathrm{Fe}^{2+}$, etc.) on the catalytic efficiency of SrtA and the most suitable concentration of $\mathrm{Ca}^{2+}$ for SrtA activity were unknown. As shown in Fig. $7, \mathrm{Ca}^{2+}$ could enhance the
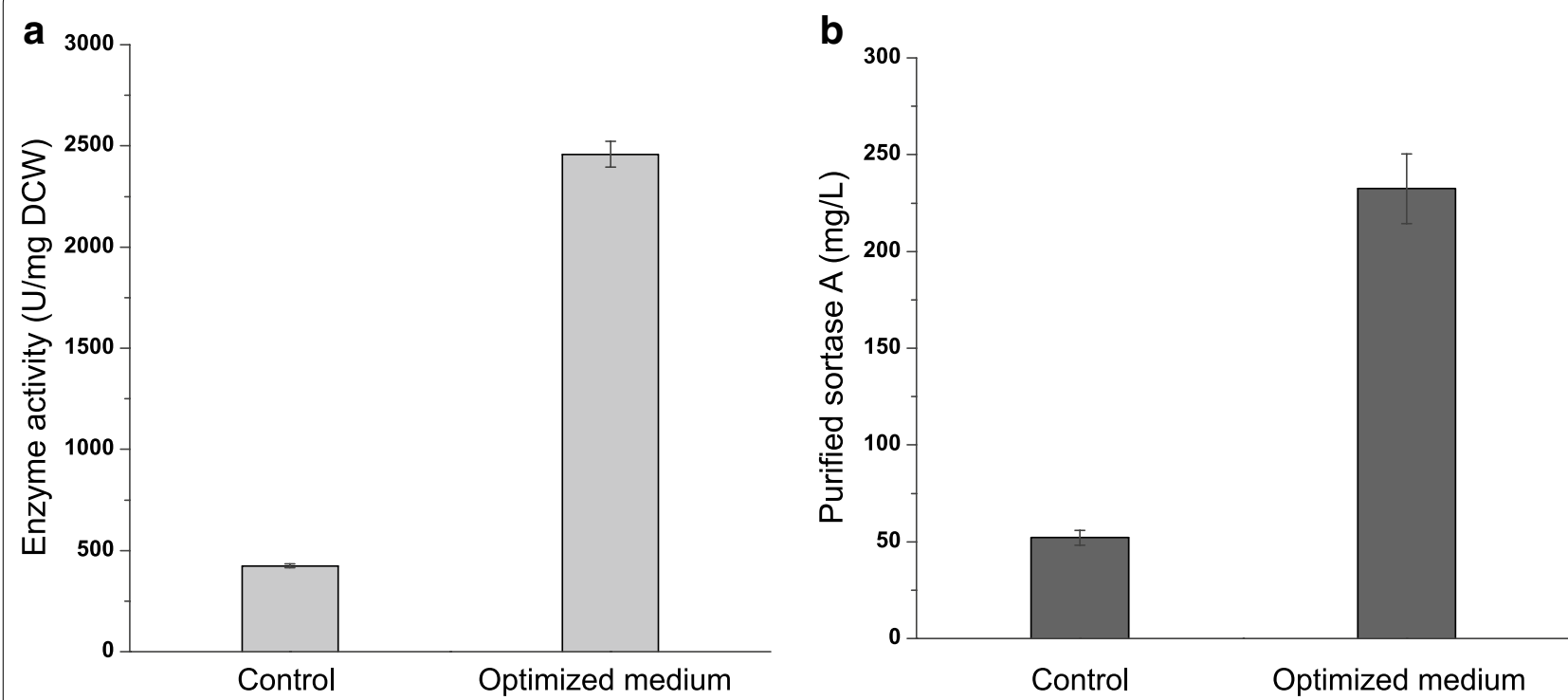

Fig. 5 Validation of the optimal conditions for SrtA expression. The LB medium was used as the control at $37^{\circ} \mathrm{C}$ for $4-\mathrm{h}$ fermentation, while the optimized media ( $0.48 \mathrm{~g} / \mathrm{L}$ glycerol, $1.37 \mathrm{~g} / \mathrm{L}$ tryptone, $0.51 \mathrm{~g} / \mathrm{L}$ yeast extract, MOPS $0.5 \mathrm{~g} / \mathrm{L}, \mathrm{PBS}$ buffer $180 \mathrm{~mL} / \mathrm{L})$ were operated at $30{ }^{\circ} \mathrm{C}$ for $8 \mathrm{~h}$. a The SrtA activity in the control and optimized media at 7- $L$ fermentor level; $\mathbf{b}$ the concentration of purified SrtA in the control and optimized media at 7-L fermentor level

Table 3 The enzyme activity and yield of SrtA performed in the optimized conditions (optimized medium, $30^{\circ} \mathrm{C}$ for $8 \mathrm{~h}$ ) and initial conditions (LB medium, $37^{\circ} \mathrm{C}$ for $4 \mathrm{~h}$ ) with shaking-flask fermentation and at 7-L fermentor level

\begin{tabular}{|c|c|c|c|c|}
\hline \multirow[t]{2}{*}{ Samples } & \multicolumn{2}{|l|}{ Shaking-flask level } & \multicolumn{2}{|l|}{ 7-L fermentor level } \\
\hline & Activity (U/mg DCW) & Yield (mg/L) & Activity (U/mg DCW) & Yield (mg/L) \\
\hline Initial conditions & $855.2 \pm 95.1$ & $44.2 \pm 2.1$ & $423.9 \pm 8.8$ & $52.1 \pm 3.9$ \\
\hline Predicted values & 1674 & 155 & - & - \\
\hline Optimized conditions & $1732.3 \pm 122.4$ & $188.1 \pm 18.3$ & $2458.4 \pm 115.9$ & $232.4 \pm 21.1$ \\
\hline
\end{tabular}




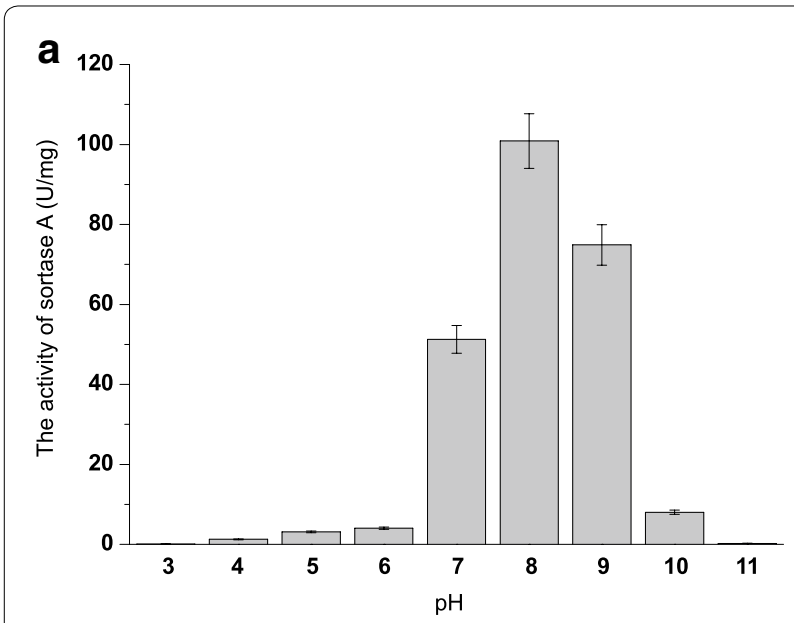

activity of SrtA dramatically, which is consistent with the literature data. The inhibition effect on SrtA in the presence of other metal ions in the decreasing order is $\mathrm{Cu}^{2}$ ${ }^{+}>\mathrm{Zn}^{2+}>\mathrm{Ni}^{2+}>\mathrm{Co}^{2+}>\mathrm{Fe}^{2+}>\mathrm{Mg}^{2+}>\mathrm{Mn}^{2+}$. As for the optimal concentration of $\mathrm{Ca}^{2+}$, there was positive correlation between SrtA activity and calcium concentration to certain extent, and the best concentration of $\mathrm{Ca}^{2+}$ for SrtA activity is $30 \mathrm{mM}$ (Fig. 8). Finally, organic solvents were frequently used as co-solvents to help in dissolving substrates in the SrtA-mediated reaction (Madej et al. 2012). The tolerance of SrtA to water-soluble organic solvents was examined. As shown in Fig. 9, SrtA is tolerant to $10 \%$ of methanol, ethanol, acetonitrile, and acetone; the enzyme activities remained at 72, 59, 70 and

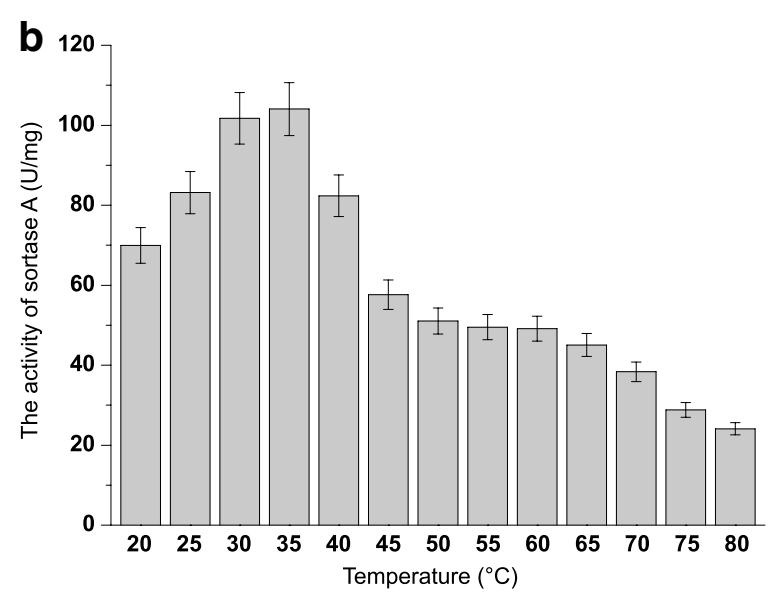

Fig. 6 The optimal $\mathrm{pH}$ and temperature for SrtA. a Effect of $\mathrm{pH}$ on SrtA activity under a $\mathrm{pH}$ range of 3-11; $\mathbf{b}$ effect of temperature on SrtA activity at various temperatures ranging from 20 to $80^{\circ} \mathrm{C}$

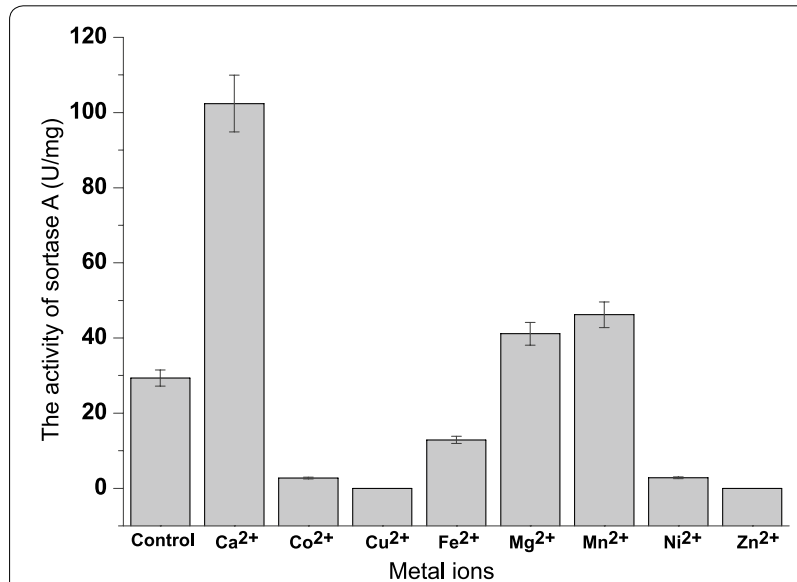

Fig. 7 Effects of metal ions (5 mM) on SrtA activity. Effect of metal ions on SrtA activity. The enzyme assays were performed in the absence (control) and the presence of $5 \mathrm{mM}$ various metal ions of $\mathrm{Ca}^{2+}, \mathrm{Co}^{2+}, \mathrm{Cu}^{2+}, \mathrm{Fe}^{2+}, \mathrm{Mg}^{2+}, \mathrm{Mn}^{2+}, \mathrm{Ni}^{2+}$, and $\mathrm{Zn}^{2+}$

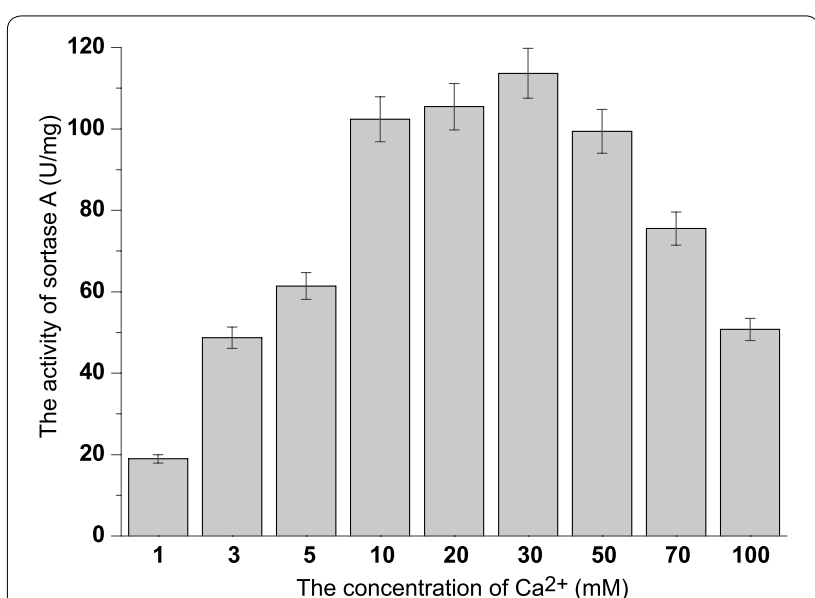

Fig. 8 Effect of $\mathrm{Ca}^{2+}$ concentration on SrtA activity. Effect of $\mathrm{Ca}^{2+}$ concentration on SrtA activity in the range of 1-100 $\mathrm{mM} \mathrm{Ca}^{2+}$

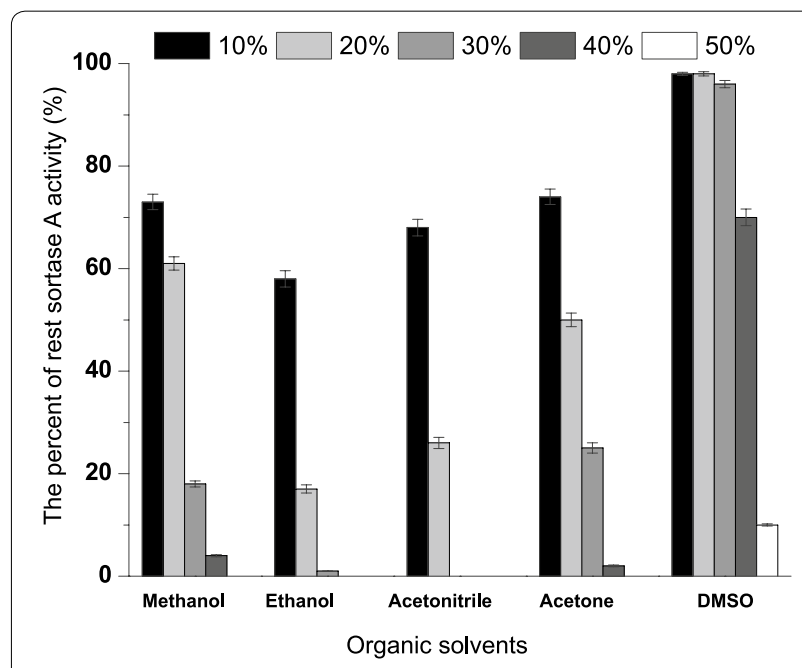

Fig. 9 Effect of organic solvents on SrtA activity. Effects of organic solvents on SrtA activity in the presence of 10-50\% of methanol, ethanol, acetonitrile, acetone, and DMSO 
73\%, respectively; and SrtA lost its majority of activities with the increasing concentrations of these solvents to $30 \%$. However, SrtA is well tolerant to dimethyl sulfoxide (DMSO) up to as high as $30 \%$ without any obvious activity loss. $40 \%$ of DMSO could decrease the enzyme activity to 70 , and $50 \%$ of DMSO is detrimental to its activity.

\section{Conclusion}

In summary, high-level expression of enzyme SrtA was achieved by a combination of single-factor optimization and response surface methodology in this study. Applying optimized medium $(0.48 \mathrm{~g} / \mathrm{L}$ glycerol, $1.37 \mathrm{~g} / \mathrm{L}$ tryptone, $0.51 \mathrm{~g} / \mathrm{L}$ yeast extract, MOPS $0.5 \mathrm{~g} / \mathrm{L}$, and PBS buffer $180 \mathrm{~mL} / \mathrm{L})$ and conditions $\left(30{ }^{\circ} \mathrm{C}\right.$ for $8 \mathrm{~h}$ ), the highest enzyme activity and yield of SrtA could reach up to $2458.4 \pm 115.9 \mathrm{U} / \mathrm{mg} \mathrm{DCW}$ and $232.4 \pm 21.1 \mathrm{mg} / \mathrm{L}$, respectively. This formulation will have potential application of production levels of SrtA on an industry scale. In addition, the detailed enzymatic characterizations of SrtA were examined, which will provide a useful guide for its future application.

\section{Additional file}

Additional file 1. Additional tables.

\section{Authors' contributions}

ZW and XZ deigned the experiment and analyzed the data, $\mathrm{HH}$ and $\mathrm{XW}$ performed the experiments. All the authors read and approved the final manuscript.

\section{Author details \\ ${ }^{1}$ The Key Laboratory of Carbohydrate Chemistry and Biotechnology, Ministry of Education, School of Biotechnology, Jiangnan University, 1800 Lihu Road, Wuxi, China. ${ }^{2}$ State Key Laboratory of Natural and Biomimetic Drugs, Peking University, Beijing 100191, China.}

\section{Acknowledgements}

Not applicable.

\section{Competing interests}

The authors declare that they have no competing interests.

\section{Ethics approval, consent to participate, and consent for publication} All authors have read and approved to submit it to Bioresources and Bioprocessing. There is no conflict of interest of any author in relation to the submission.

\section{Funding}

This work was supported by the National Natural Science Foundation of China (21472070), the Project for Jiangsu Scientific and Technological Innovation Team, the Fund for Jiangsu Distinguished Professorship Program, and the State Key Laboratory of Natural and Biomimetic Drugs (K20140216), The Project was funded by the Priority Academic Program Development of Jiangsu Higher Education Institutions, the 111 Project (No. 111-2-06), and the Jiangsu province "Collaborative Innovation Center for Advanced Industrial Fermentation" industry development program.

Received: 5 December 2016 Accepted: 7 February 2017

Published online: 18 February 2017

\section{References}

Beerli RR, Hell T, Merkel AS, Grawunder U (2015) Sortase enzyme-mediated generation of site-specifically conjugated antibody drug conjugates with high in vitro and in vivo potency. PLOS ONE 10:131177

Bentley ML, Lamb EC, McCafferty DG (2008) Mutagenesis studies of substrate recognition and catalysis in the sortase A transpeptidase from Staphy/ococcus aureus. J Biol Chem 283:14762-14771

Buchanan RL, Klawitter LA (1992) The effect of incubation temperature, initial $\mathrm{pH}$, and sodium chloride on the growth kinetics of Escherichia coli O157:H7. Food Microbiol 9:185-196

Chan L, Cross HF, She JK, Cavalli G, Martins HF, Neylon C (2007) Covalent attachment of proteins to solid supports and surfaces via sortase-mediated ligation. PLOS ONE 2:e1164

Glasgow JE, Salit ML, Cochran JR (2016) In vivo site-specific protein tagging with diverse amines using an engineered sortase variant. J Am Chem Soc 138:7496-7499

Guo X, Wang Q, Swarts BM, Guo Z (2009) Sortase-catalyzed peptideglycosylphosphatidylinositol analogue ligation. J Am Chem Soc 131:9878-9879

Hirakawa H, Ishikawa S, Nagamune T (2012) Design of $\mathrm{Ca}^{2+}$-independent Staphylococcus aureus sortase A mutants. Biotechnol Bioeng 109:2955-2961

Ilangovan U, Ton-That H, Iwahara J, Schneewind O, Clubb RT (2001) Structure of sortase, the transpeptidase that anchors proteins to the cell wall of Staphylococcus aureus. Proc Natl Acad Sci USA 98:6056-6061

Kim SW, Chang IM, Oh KB (2002) Inhibition of the bacterial surface protein anchoring transpeptidase sortase by medicinal plants. Biosci Biotechnol Biochem 66:2751-2754

Kruger RG, Dostal P, McCafferty DG (2004) Development of a high-performance liquid chromatography assay and revision of kinetic parameters for the Staphylococcus aureus sortase transpeptidase SrtA. Anal Biochem 326:42-48

Lee C, Sun WJ, Burgess BW, Junker BH, Reddy J, Buckland BC et al (1997) Process optimization for large-scale production of TGF-alpha-PE40 in recombinant Escherichia coli: effect of medium composition and induction timing on protein expression. J Ind Microbiol Biotechnol 18:260-266

Lee KY, Shin DS, Yoon JM, Heonjoong K, Oh KB (2002) Expression of sortase, a transpeptidase for cell wall sorting reaction, from Staphylococcus aureus ATCC 6538p in Escherichia coli. J Microbiol Biotechnol 12:530-533

Li Z, Nimtz M, Rinas U (2014) The metabolic potential of Escherichia coli BL21 in defined and rich medium. Microb Cell Fact 13:45

Madej MP, Coia G, Williams CC, Caine JM, Pearce LA, Attwood R et al (2012) Engineering of an anti-epidermal growth factor receptor antibody to single chain format and labeling by sortase A-mediated protein ligation. Biotechnol Bioeng 109:1461-1470

Matsushita T, Sadamoto R, Ohyabu N, Nakata H, Fumoto M, Fujitani N et al (2009) Functional neoglycopeptides: synthesis and characterization of a new class of MUC1 glycoprotein models having core 2-based O-glycan and complex-type N-glycan chains. Biochemistry 48:11117-11133

Mazmanian SK, Liu G, Ton-That H, Schneewind O (1999) Staphylococcus aureus sortase, an enzyme that anchors surface proteins to the cell wall. Science 285:760-763

Naik MT, Suree N, llangovan U, Liew CK, Thieu W, Campbell DO et al (2006) Staphylococcus aureus Sortase A transpeptidase. Calcium promotes sorting signal binding by altering the mobility and structure of an active site loop. J Biol Chem 281:1817-1826

Papaneophytou CP, Kontopidis G (2014) Statistical approaches to maximize recombinant protein expression in Escherichia coli: a general review. Protein Expr Purif 94:22-32

Perry AM, Ton-That H, Mazmanian SK, Schneewind O (2002a) Anchoring of surface proteins to the cell wall of Staphylococcus aureus. III. Lipid II is an in vivo peptidoglycan substrate for sortase-catalyzed surface protein anchoring. J Biol Chem 277:16241-16248

Perry AM, Ton-That H, Mazmanian SK, Schneewind O (2002b) Anchoring of surface proteins to the cell wall of Staphylococcus aureus. III. Lipid II is an in vivo peptidoglycan substrate for sortase-catalyzed surface protein anchoring. J Biol Chem 277:16241-16248

Scott CJ, McDowell A, Martin SL, Lynas JF, Vandenbroeck K, Walker B (2002) Irreversible inhibition of the bacterial cysteine protease-transpeptidase sortase (SrtA) by substrate-derived affinity labels. Biochem J 366:953-958 
Tanaka T, Yamamoto T, Tsukiji S, Nagamune T (2008) Site-specific protein modification on living cells catalyzed by Sortase. ChemBioChem 9:802-807

Ton-That H, Liu G, Mazmanian SK, Faull KF, Schneewind O (1999) Purification and characterization of sortase, the transpeptidase that cleaves surface proteins of Staphylococcus aureus at the LPXTG motif. Proc Natl Acad Sci USA 96:12424-12429

Tseng CL, Leng CH (2012) Influence of medium components on the expression of recombinant lipoproteins in Escherichia coli. Appl Microbiol Biotechnol 93:1539-1552

Vincentelli R, Romier C (2013) Expression in Escherichia coli: becoming faster and more complex. Curr Opin Struct Biol 23:326-334

Voloshchuk N, Liang D, Liang JF (2015) Sortase A mediated protein modifications and peptide conjugations. Curr Drug Disc Technol 12:205-213
Witte MD, Cragnolini JJ, Dougan SK, Yoder NC, Popp MW, Ploegh HL (2012) Preparation of unnatural N-to-N and C-to-C protein fusions. Proc Natl Acad Sci USA 109:11993-11998

Wu Z, Guo X, Wang Q, Swarts BM, Guo Z (2010) Sortase A-catalyzed transpeptidation of glycosylphosphatidylinositol derivatives for chemoenzymatic synthesis of GPI-anchored proteins. J Am Chem Soc 132:1567-1571

Wu Z, Guo X, Guo Z (2011) Sortase A-catalyzed peptide cyclization for the synthesis of macrocyclic peptides and glycopeptides. Chem Commun 47:9218-9220

Wu Z, Guo X, Gao J, Guo Z (2013) Sortase A-mediated chemoenzymatic synthesis of complex glycosylphosphatidylinositol-anchored protein. Chem Commun 49:11689-11691

\section{Submit your manuscript to a SpringerOpen ${ }^{\circ}$ journal and benefit from:}

- Convenient online submission

- Rigorous peer review

- Immediate publication on acceptance

- Open access: articles freely available online

- High visibility within the field

- Retaining the copyright to your article 